\title{
Exclusive breastfeeding and rotavirus vaccination are associated with decreased diarrheal morbidity among under-five children in Bahir Dar, northwest Ethiopia
}

Ghion Shumetie ${ }^{1}$, Molla Gedefaw ${ }^{2}$, Adane Kebede $^{3}$ and Terefe Derso ${ }^{4 *}$

* Correspondence:

dersotere@gmail.com

${ }^{4}$ Department of Human Nutrition, Institute of Public Health, College of Medicine and Health Sciences, University of Gondar, Gondar, Ethiopia

Full list of author information is available at the end of the article

\begin{abstract}
Background: More than one in every ten (14\%) of under-five child deaths is associated with diarrheal morbidity in Ethiopia. Although Ethiopia has implemented different health interventions like its immunization program, childhood diarrhea morbidity, on which literature is limited, continues as a public health problem. Hence, the aim of this study was to assess the prevalence of diarrheal morbidity and associated factors among under-five children in Bahir Dar, northwest Ethiopia.
\end{abstract}

Method: A community based cross-sectional study was carried out from March 05 to April 03/2015 in Bahir Dar in which 553 mother-child pairs participated. A structured questionnaire was adapted from the World Health Organization (WHO) and the Ethiopian Demography and Health Survey (EDHS) to collect the data. Bivariate and multivariate logistic regression analyses were carried out to identify the independent predictors of diarrheal morbidity.

Result: The overall prevalence of diarrheal morbidity was 9.4\% [95\% Confidence Interval (Cl): 4.8, 14.0\%]. No receipt of Rotavirus vaccine dose 2 [AOR $=3.96,95 \% \mathrm{Cl} ; 2.13$, 7.33], non-exclusive breastfeeding [AOR $=2.69,95 \% \mathrm{Cl} ; 1.39,5.19]$, unavailability of solid waste disposal system $[\mathrm{AOR}=2.62,95 \% \mathrm{Cl} ; 1.19,5.77]$, employed and private business occupational status of mothers $[\mathrm{AOR}=2.10,95 \% \mathrm{Cl} ; 1.02,4.31)]$, and less than Ethiopia Birr (ETB) 600 household monthly income $[\mathrm{AOR}=2.10,95 \% \mathrm{Cl} ; 1.2,7.2]$ were independently associated with diarrheal morbidity.

Conclusion: In Bahir Dar, one in every ten of the under-five children surveyed suffered from diarrheal morbidity. Thus, implementing effective rotavirus vaccination programs, encouraging exclusive breastfeeding and emphasizing appropriate solid waste management would reduce childhood diarrheal morbidity in the region. In addition, the finding suggests that improved child care mechanisms, especially for mothers working outside the home, and efforts to increase household income should be intensified to reduce incidence of diarrhea.

Keywords: Diarrheal morbidity, Rotavirus vaccination, Under five, Ethiopia 


\section{Background}

Diarrhea is associated with many common childhood infectious diseases and one of the immediate causes of undernutrition, which in turn interferes with physical growth, mental development, and increases the risk of death [1,2]. It remains the second leading cause of death in children under 5 years of age, and $90 \%$ of the burden is in resource limited settings [1,3]. About $50 \%$ of childhood morbidity and $50-80 \%$ of childhood mortality is associated with diarrhea in Sub-Saharan Africa [4, 5]. Each year, an estimated 2.5 billion cases of diarrhea occur among under-five children, but the incidence has been relatively stable over the past two decades [6]. In resource limited countries, poor declining trend of diarrheal disease is associated with multiple reasons such as, poor environmental sanitation, low educational status of mothers, and other behavioral issues $[7,8]$.

A variety of bacterial, viral, and parasitic organisms are able to spread through contaminated food or drinking water or from person to person as a result of poor hygiene [2]. Rotavirus in particular is the most common etiological agent of diarrhea both in high and low income countries, and 6\% of all child death globally is associated with it $[9,10]$, and child diarrheal morbidity mostly depends on the interaction of behavioral, socio-economic, and environmental factors [11, 12]. Various studies in different settings have explored that unavailability of water, lack of hand washing facilities, hand washing with water only, private business, children aged between 6 and 24 months, illiteracy of mothers, delay to initiate breastfeeding, no breastfeeding, and lack of exclusive breastfeeding were positively associated with diarrheal morbidity [13-16]. On the other hand, rotavirus vaccination has a protective effect on diarrheal morbidity [16].

Ethiopia is implementing health strategies $[17,18]$ and immunization programs, including more recently rotavirus vaccination, to prevent the burden of diarrheal morbidity [19]. However, about $21 \%$ of under-five children are still suffering from diarrhea due to rotavirus [20]. Also, more than one in every ten (14\%) of under-five child deaths is associated with diarrhea morbidity in the country [21]. According to the Ethiopian Demographic and Health Survey, the prevalence of diarrheal disease in under-five children in the 2 weeks before the survey has dropped from 18\% in 2005 to $13 \%$ in 2011 $[22,23]$. Conducting a study in an evidence dearth setting is critical to explore information on diarrheal morbidity and its determinants. The study is expected to provide a prominent input to policymakers and program managers about the implementation of current strategies, including rotavirus vaccination. Therefore, the aim of this study was to assess the prevalence and associated factors of diarrheal morbidity among under-five children in Bahir Dar, northwest Ethiopia.

\section{Methods}

Study setting and design

A community based cross-sectional study was carried out from March 05 to April 03, 2015 in Bahir Dar, the capital of Amhara national regional state, which has an estimated population of 297,749 [24]. Bahir Dar is located $565 \mathrm{~km}$ from Addis Ababa in Amhara national regional state in northwest Ethiopia. The major economic sectors of the city are horticulture, commerce, agro-industrial processing, urban agriculture, manufacturing, and diverse service industries. Bahir Dar is also one of the leading tourist destinations in 
Ethiopia; attractions include the nearby Lake Tana and Blue Nile river. Currently, Bahir Dar is divided into 19, 9 urban and 10 rural kebeles (smallest administrative unit). According to the zonal health department, the city administration has 1 referral hospital, 1 zonal governmental hospital, 10 government health centers, 10 health posts, one private hospital, 10 advanced and 17 medium clinics, and 12 small private clinics which provide comprehensive health services including vaccination. Four, 2 urban and 2 rural kebeles (Zenzelima, Sefen Selam, Shimbete and Meshenti) were selected out of 19 kebeles by lottery method (Fig. 1).

\section{Study population and sampling procedure}

All mothers/caregivers with under-five children who lived in Bahir Dar for at least 6 months were included in this study. Sample size was calculated using the single population proportion formula on the following assumptions: $95 \%$ confidence interval, $5 \%$ margin of error, prevalence of diarrhea $21.5 \%$ in Jabithennan district, northwest Ethiopia [25], 10\% non-response rate, and a design effect of $2 \%$. The final calculated sample size was 572. A multistage sampling technique was employed to select participants; initially, the list of the dwellers of the 19 kebeles was taken from the city administration. Four kebeles were selected using the lottery method. Then, the computed sample size was proportionally allocated according to the number of under-five children in each kebele. Finally, a systematic sampling technique was employed to obtain the required study participants. In cases of more than one study child in a household, the simple random sampling method was used to select a single participant. The outcome variable, diarrhea morbidity, is the presence of three and more loose or liquid stools per day within the 2 -week period prior to survey.

\section{Data collection tools and procedures}

A structured questionnaire was adapted from the World Health Organization (WHO) and the Ethiopian Demography and Health Survey (EDHS) to collect the data [23, 26].

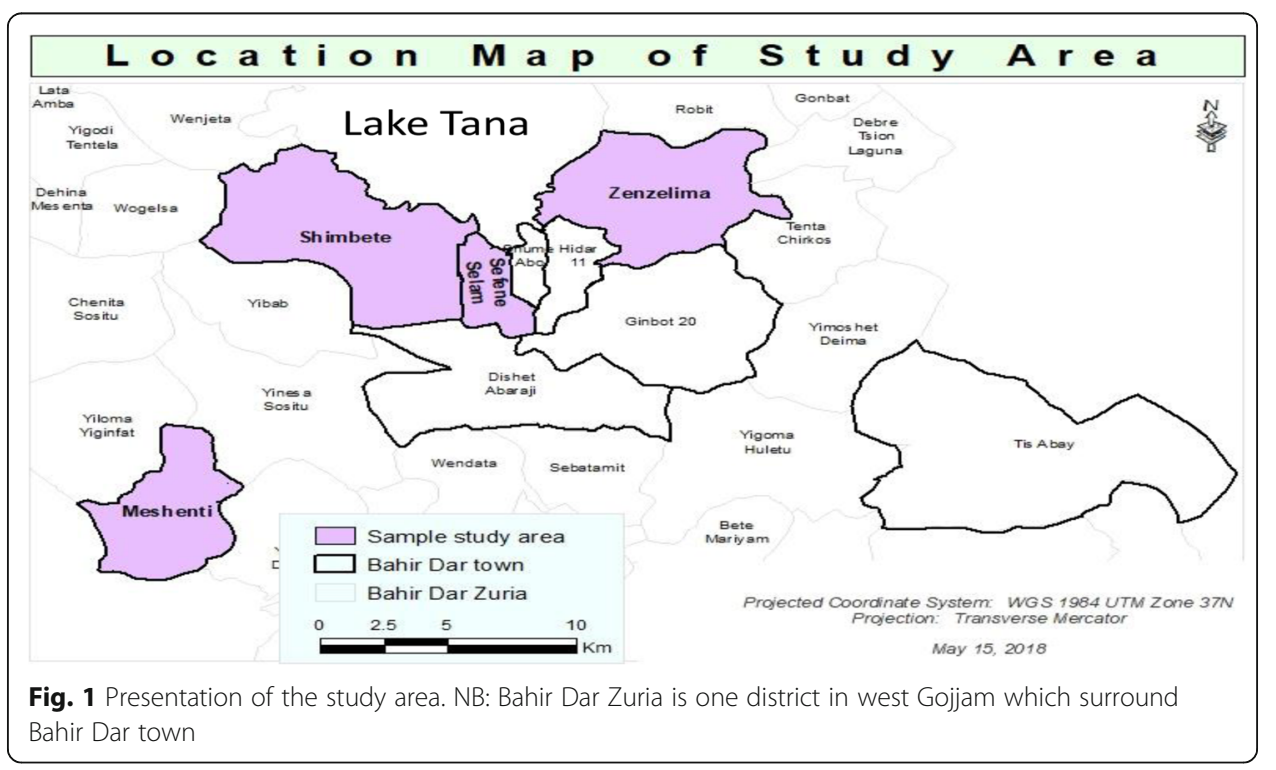


The questionnaire was composed of socio-demographic, maternal and child characteristics, child feeding practices, environmental health conditions, and the outcome interest (diarrhea morbidity). Eight diploma graduate and four BSc nurses were recruited for data collection and supervision, respectively. One-day training was given to data collectors and supervisors. A pretest was administered out of the actual study area. After a few modifications like clarifying the ambiguity of word expressions, the questionnaire was administered in the local language, Amharic.

\section{Data analysis}

Data were entered into the EPI-info version7 statistical software and exported to SPSS version 20 statistical package for analysis. Frequencies and proportions were used to summarize variables in tables. The association between diarrhea morbidity and each independent variable was assessed using the binary logistic regression model. Variables significant at $P$ value $<0.2$ in the bivariate analysis were further entered into the multivariate analysis. The significance of association was determined at a $P$ value of $<0.05$ in the multivariate analysis, while the strength of association was measured by adjusted odds ratio with $95 \%$ confidence interval.

\section{Results}

\section{Socio-demographic and behavioral characteristics of study participants}

In this study, 553 eligible under five years children were included with a response rate of $96.7 \%$. More than three-fourths of the participating mothers (80.5\%) were married, and $83.2 \%$ had primary school and above educational status. The majority of the mothers $(61.7 \%)$ were employed or in private business with $41.6 \%$ of their children ranging in age from 7 to 24 months.

Nine in every ten $(91.7 \%)$ of the households had latrine facilities. However, $71.1 \%$ had no hand washing facilities near toilets. Three fourths $(76.9 \%)$ of the participants had a habit of hand washing after visiting toilets. However, more than half (57.9\%) of the participants were practiced hand washing without using detergents. Two-thirds of children were vaccinated with rotavirus vaccine dose $1(66.5 \%)$ and dose 2 (64.0\%). $71.6 \%$ of under-five children were exclusively breastfed for 6 months (Table 1).

\section{Prevalence of diarrhea}

Approximately, one in every ten (9.4\%) (95\% CI: 4.8, 14.0) of the under-five children had diarrheal morbidity in the 2 weeks preceding the survey.

\section{Factors associated with diarrheal morbidity}

The odds of diarrheal morbidity was higher among children who were not exclusively breastfed for 6 months [AOR $=2.69,95 \% \mathrm{CI} ; 1.39,5.19]$, and who had no receipt of rotavirus vaccine dose $2[\mathrm{AOR}=3.96,95 \% \mathrm{CI} ; 2.13,7.33$ ] compared to children who were exclusively breastfed for 6 months and with receipt of rotavirus vaccine dose 2, respectively. Children from households that had no solid waste disposal systems $[\mathrm{AOR}=2.62$, $95 \% \mathrm{CI} ; 1.19,5.77]$ were more likely to develop diarrheal morbidity compared to children from households with availability of solid waste disposal systems. Employed and private business occupational status of mothers $[\mathrm{AOR}=2.10,95 \% \mathrm{CI} ; 1.02,4.31]$ and $\leq \mathrm{ETB} 600$ 
Table 1 Socio-demographic and behavioral characteristics of study participants in Bahir Dar city administration, northwest Ethiopia, 2015

\begin{tabular}{|c|c|c|}
\hline Characteristics & Frequency & Percentage (\%) \\
\hline \multicolumn{3}{|l|}{ Age of mothers in years } \\
\hline $15-24$ & 186 & 33.6 \\
\hline $25-35$ & 292 & 52.8 \\
\hline$>35$ & 75 & 13.6 \\
\hline \multicolumn{3}{|l|}{ Current marital status } \\
\hline Married & 445 & 80.5 \\
\hline Unmarried & 108 & 19.5 \\
\hline \multicolumn{3}{|l|}{ Religion } \\
\hline Orthodox & 403 & 72.9 \\
\hline Muslim & 100 & 18.1 \\
\hline Protestant and Catholic & 50 & 9.0 \\
\hline \multicolumn{3}{|l|}{ Age of child } \\
\hline $0-6$ months & 105 & 19.0 \\
\hline 7-24 months & 230 & 41.6 \\
\hline$>24$ months & 218 & 39.4 \\
\hline \multicolumn{3}{|l|}{ Sex of child } \\
\hline Male & 283 & 51.2 \\
\hline Female & 270 & 48.8 \\
\hline \multicolumn{3}{|l|}{ Monthly income of household } \\
\hline$\leq 600$ & 221 & 40.0 \\
\hline $601-2000$ & 156 & 28.2 \\
\hline$\geq 2001$ & 176 & 31.8 \\
\hline \multicolumn{3}{|l|}{ Mothers educational status } \\
\hline Uneducated & 93 & 16.8 \\
\hline Educated & 460 & 83.2 \\
\hline \multicolumn{3}{|l|}{ Mothers occupation } \\
\hline Housewife & 212 & 38.3 \\
\hline Employed and private business & 341 & 61.7 \\
\hline \multicolumn{3}{|l|}{ Latrine availability } \\
\hline No & 46 & 8.3 \\
\hline Yes & 507 & 91.7 \\
\hline \multicolumn{3}{|l|}{ Sanitation facilities } \\
\hline Improved sanitation facilities* & 231 & 41.77 \\
\hline Unimproved sanitation facilities** & 322 & 58.23 \\
\hline \multicolumn{3}{|l|}{ Availability of solid waste facility } \\
\hline No & 110 & 19.9 \\
\hline Yes & 443 & 80.1 \\
\hline \multicolumn{3}{|l|}{ Hand washing facility near toilet } \\
\hline No & 393 & 71.1 \\
\hline Yes & 160 & 28.9 \\
\hline \multicolumn{3}{|l|}{ Availability of liquid waste facility } \\
\hline No & 371 & 67.1 \\
\hline Yes & 182 & 32.9 \\
\hline
\end{tabular}


Table 1 Socio-demographic and behavioral characteristics of study participants in Bahir Dar city administration, northwest Ethiopia, 2015 (Continued)

\begin{tabular}{|c|c|c|}
\hline Characteristics & Frequency & Percentage (\%) \\
\hline \multicolumn{3}{|l|}{ Source of water } \\
\hline Improved drinking water sources ${ }^{1}$ & 455 & 82.2 \\
\hline Unimproved drinking water sources ${ }^{2}$ & 98 & 17.8 \\
\hline Protected spring water & 1 & .2 \\
\hline Unprotected well, spring and surface water & 32 & 5.8 \\
\hline \multicolumn{3}{|l|}{ Trend of using toilet } \\
\hline Always & 465 & 84.1 \\
\hline Rarely & 46 & 8.3 \\
\hline Not at all & 42 & 7.6 \\
\hline \multicolumn{3}{|l|}{ Hand wash practice } \\
\hline No & 128 & 23.1 \\
\hline Yes & 425 & 76.9 \\
\hline \multicolumn{3}{|l|}{ Rotavirus vaccine dose 1} \\
\hline No & 185 & 33.5 \\
\hline Yes & 368 & 66.5 \\
\hline \multicolumn{3}{|l|}{ Rotavirus vaccine dose 2} \\
\hline No & 199 & 36.0 \\
\hline Yes & 354 & 64.0 \\
\hline \multicolumn{3}{|l|}{ Antenatal care } \\
\hline No & 99 & 17.9 \\
\hline Yes & 454 & 82.1 \\
\hline \multicolumn{3}{|l|}{ Exclusive breastfeeding } \\
\hline No & 157 & 28.4 \\
\hline Yes & 396 & 71.6 \\
\hline \multicolumn{3}{|l|}{ Current breastfeeding status } \\
\hline Breast milk only & 92 & 16.6 \\
\hline Partially & 327 & 59.1 \\
\hline No breast feed currently & 134 & 24.2 \\
\hline
\end{tabular}

*Pour-flush latrine, ventilated improved pit latrine, **Open pit latrine, communal and open filed

${ }^{1}$ Pipe, protected well and protected spring water $a,{ }^{2}$ Unprotected well, spring and surface water

monthly income of households $[\mathrm{AOR}=2.10,95 \% \mathrm{CI} ; 1.2,7.2]$ were significantly associated with diarrheal morbidity as compared to their counterparts (Table 2).

\section{Discussion}

In the current study, approximately one in every ten (9.4\%) (95\% CI: 4.8, 14.0) of under-five children suffered from diarrheal morbidity; children with no receipt of rotavirus vaccine dose 2 , no exclusive breastfeeding, unavailability of a solid waste disposal system, employed and private business occupational status of mothers, and household monthly income less than ETB 2000 were independent predictors of diarrheal morbidity.

The prevalence of diarrheal morbidity was similar to the national report of 13\% [23] and other local studies in hot spot districts of the Amhara region (13.5\%) [27], Hawassa (11.7\%) [28], and Jigjiga town (14.6\%) [13]. However, the current finding was lower than reported from Hadaleala district, Afar region, Ethiopia (31.3\%) [16]. The high 
Table 2 Predictors of diarrheal morbidity in Bahir Dar town administration, northwest Ethiopia, May, 2015

\begin{tabular}{|c|c|c|c|c|}
\hline \multirow{2}{*}{$\begin{array}{l}\text { Explanatory variable } \\
\text { Sex of the child }\end{array}$} & \multicolumn{2}{|c|}{$\begin{array}{l}\text { Diarrheal morbidity } \\
\text { Yes No }\end{array}$} & \multirow[t]{2}{*}{ Crude odds ratio( $95 \% \mathrm{Cl})$} & \multirow[t]{2}{*}{ Adjusted odds ratio( $95 \% \mathrm{Cl})$} \\
\hline & & & & \\
\hline Male & 33 & 250 & $1.74(0.97,3.15)$ & $1.65(0.89,3.05)$ \\
\hline Female & 19 & 251 & 1.00 & 1.00 \\
\hline \multicolumn{5}{|l|}{ Solid waste disposal system } \\
\hline No & 15 & 95 & $1.73(0.91,3.23)$ & $2.62(1.19,5.77)$ \\
\hline Yes & 37 & 406 & 1.00 & 1.00 \\
\hline \multicolumn{5}{|l|}{ Occupation of the mothers } \\
\hline House wife & 18 & 194 & 1.00 & 1.00 \\
\hline Employed and private business & 34 & 307 & $1.19(0.66,2.17)$ & $2.10(1.02,4.31)$ \\
\hline \multicolumn{5}{|l|}{ Monthly income of the family } \\
\hline$\leq 600$ & 26 & 195 & $2.47(1.13,5.43)$ & $2.99(1.23,7.24)$ \\
\hline $601-2000$ & 9 & 139 & $2.27(0.96,5.25)$ & $2.65(0.99,6.67)$ \\
\hline$\geq 2001$ & 52 & 167 & 1.00 & 1.00 \\
\hline \multicolumn{5}{|l|}{ Rotavirus vaccine dose 2} \\
\hline No & 32 & 167 & $3.20(1.78,5.77)$ & $3.96(2.13,7.33)$ \\
\hline Yes & 20 & 334 & 1.00 & 1.00 \\
\hline \multicolumn{5}{|l|}{ Exclusive breastfeeding } \\
\hline No & 22 & 135 & $1.20(1.11,3.57)$ & $2.69(1.39,5.19)$ \\
\hline Yes & 30 & 266 & 1.00 & 1.00 \\
\hline
\end{tabular}

Hosmer and Lemeshow goodness of fit test was checked; the result was 0.76

prevalence in Afar region compared to the current study might be due to the nomadic nature of the population. Nomads may not have access to basic health care, water, and sanitation services due to their migration from place to place in search of pasture and water. Nomads have no permanent residence and practice open defecation. The main sources of water are rivers, streams, and wells; hence, they are prone to contamination and diarrheal diseases, especially children who routinely play in the unhygienic environment [29].

This study found that children who did not receive rotavirus vaccine dose 2 suffered 3.96 times more from diarrheal morbidity compared to those in receipt of rotavirus vaccine dose 2. A similar local study on children who did not receive rotavirus vaccine dose 2 showed that children suffered from diarrheal morbidity [16]. This might be due to the fact that rotavirus vaccinated children are immunized from the highest impact of acute gastroenteritis (AGE) morbidity in Africa, where the burden of disease is the greatest [30]. This implies that rotavirus vaccination is one of the best ways to prevent diarrheal morbidity and its consequences. Thus, two-dose rotavirus vaccines (dose 1 and 2) should be given for children as part of a comprehensive approach to control diarrhea.

The odds of diarrheal morbidity were 2.69 times higher among under-five children who were not exclusively breastfed for 6 months. A similar finding was observed in nomadic populations of Ethiopia; children who were not exclusively breastfed suffered from diarrheal morbidity [16]. Breast milk contains all the nutrients that an infant needs in the first 6 months of life. Additionally, breast milk contains bioactive factors that augment infants' immature immune system, providing protection against infection. Also, breast milk is available all the time and is practically free from pathogenic 
microorganisms. On the other hand, non-exclusive breastfeeding is an important risk factor of infant diseases like diarrheal morbidity. This finding suggest that exclusive breastfeeding during the first 6 months of life is one of the most effective interventions to improve child health [31].

Like the local study from Debrebirehan town [15], the current study found that employed and private business occupational status of mothers was significantly associated with diarrheal morbidity in under-five children compared to housewife mothers occupational status. The possible explanation might be that mothers working outside the home may have less time to better care and feed their children compared to housewives. Another possible reason might be that mothers working outside the home may not have as much contact time to breastfeed their children as compared with housewives.

According to this study, children from households that had no solid waste disposal systems were more likely to develop diarrheal diseases. This study is consistent with another local study in northwest Ethiopia [32]. This might be due to children putting contaminated fingers, pica, or fomites into their mouths while crawling or playing around contaminated environments associated with poor waste disposal practices [29, 33].

The last significant variable, the odds of diarrheal disease, is nearly three times higher among children whose household income is SETB 600 compared to children whose household income is $\geq$ ETB 2000. It may be the case that mothers/caregivers who have higher incomes may have the opportunity to buy and use detergents for hand washing and the resources to construct and use standard toilets.

\section{Limitation}

This study showed the prevalence of diarrheal morbidity and its associated factors; like rotavirus vaccination among the most vulnerable population groups, under-five children, in Bahir Dar, Ethiopia where there is scarcity of literature. However, the study has some limitations. For example, the cross-sectional design of the study may limit its capacity to measure the cause-effect relationship between the outcome and the potential correlates. As well, there may be recall bias of diarrhea episodes/rotavirus vaccination and difficulty distinguishing the time order of exposures. Finally, wealth index is not addressed in this study.

\section{Conclusion}

In the study area, approximately one in every ten of the under-five children had diarrheal morbidity. Thus, implementing effective rotavirus vaccination programs, encouraging exclusive breastfeeding, and emphasize appropriate solid waste management would reduce childhood diarrheal morbidity in the region. In addition, the finding suggests that improved child care mechanisms, especially for mothers working outside the home, and efforts to increase household income should be intensified to reduce incidence of diarrhea.

\footnotetext{
Abbreviations

AOR: Adjusted odds ratio; Cl: Confidence interval; COR: Crude odds ratio; DDS: Dietary diversity score; EDHS: Ethiopian Demographic Health Survey; GDP: Gross Domestic Production; SPSS: Statistical Package for Social Science; VIPL: Ventilated and improved pit latrine; WHO: World Health Organization
} 
Availability of data and materials

We confirm that all data underlying the findings would be fully available without restriction if the manuscript is published.

\section{Authors' contributions}

GS and MG conceived the study, developed the tool, coordinated data collection, carried out the statistical analysis, and drafted the manuscript. AK and TD conceived the study, participated in the statistical analysis, and drafted the manuscript. TD conceived the study and reviewed the drafted manuscript. All authors read and approved the final manuscript.

\section{Ethics approval and consent to participate}

Bahir Dar University approved the study protocol, and then ethical clearance was obtained from the research and publication committee of Bahir Dar University. After explanation of the study objective, further permission was obtained from the Amhara National Regional State Health Bureau. Verbal consent was also obtained from parents or legal guardians. The confidentiality of information was quaranteed by using code numbers rather than personal identifiers and by keeping the data locked. Participants were told to decline at any time if they felt uncomfortable, even after the interview was started.

\section{Consent for publication}

Not applicable.

\section{Competing interests}

The authors declare that they have no competing interest.

\section{Publisher's Note}

Springer Nature remains neutral with regard to jurisdictional claims in published maps and institutional affiliations.

\section{Author details}

${ }^{1}$ ORDA/PSI MULU HIV Prevention Project, Bahir Dar, Amhara region, Ethiopia. ${ }^{2}$ College of Medicine and Health Science, Bahir Dar University, Bahir Dar, Ethiopia. ${ }^{3}$ Department of Health Service Management and Heath Economics, Institute of Public Health, College of Medicine and Health Sciences, University of Gondar, Gondar, Ethiopia. ${ }^{4}$ Department of Human Nutrition, Institute of Public Health, College of Medicine and Health Sciences, University of Gondar, Gondar, Ethiopia.

Received: 29 December 2017 Accepted: 2 August 2018

Published online: 01 November 2018

\section{References}

1. Glass Rl, Parashar U, Patel M, Gentsch J, Jiang B. Rotavirus vaccines: successes and challenges. J Infect. 2014;68:S9-18.

2. CDC. Epidemiology and prevention of vaccine-preventable diseases. 2012;12(2):1-4.

3. Boschi-Pinto C, Velebit L, Shibuya K. Estimating child mortality due to diarrhoea in developing countries. Bull World Health Organ. 2008;86(9):710-7.

4. WHO U. Diarrhoea: why children are still dying and what can be done. Geneva: UNICEF/WHO; 2009.

5. Walker CL, Rudan I, Liu L, Nair H, Theodoratou E, Bhutta ZA, O'Brien KL, Campbell H, Black RE. Global burden of childhood pneumonia and diarrhoea. Lancet. 2013;381(9875):1405-16.

6. WHO. Reducing mortality from major childhood killer diseases. Mort Country Fact Sheet. 2006:1-4.

7. Kumar SG, Subita L. Diarrhoeal diseases in developing countries: a situational analysis. Kathmandu Univ Med J. 2013;10(2):83-8.

8. UNICEF. Pneumonia and diarrhea: tackling the deadliest diseases in the world. New York: UNICEF; 2012.

9. Ndze VN, Akum AE, Kamga GH, Enjema LE, Esona MD, Banyai K, Therese OA. Epidemiology of rotavirus diarrhea in children under 5 years in northern Cameroon. Pan Afr Med J. 2012;11(1):1937-8688.

10. Tate JE, Burton AH, Boschi-Pinto C, Steele AD, Duque J, Parashar UD. 2008 estimate of worldwide rotavirusassociated mortality in children younger than 5 years before the introduction of universal rotavirus vaccination programmes: a systematic review and meta-analysis. Lancet Infect Dis. 2012;12(2):136-41.

11. Freij L, Kidane Y, Sterky G, Wall S. Exploring child health and its ecology. The Kirkos study in Addis Ababa. Research frame, project description and data evaluation. 1976.

12. Mosley WH, Chen LC. An analytical framework for the study of child survival in developing countries. Popul Dev Rev. 1984;10(0):25-45.

13. Bizuneh $\mathrm{H}$, Getnet $\mathrm{F}$, Meressa B, Tegene $\mathrm{Y}$, Worku G. Factors associated with diarrheal morbidity among under-five children in Jigjiga town, Somali regional state, eastern Ethiopia: a cross-sectional study. BMC Pediatr. 2017;17(1):182.

14. Rohmawati N, Panza A, Lertmaharit S. Factors associated with diarrhea among children under five years of age in Banten province. Indonesia J Health Res. 2012;26(1):31-4.

15. Mamo A, Hailu A. Assessment of prevalence and related factors of diarrheal diseases among under-five year's children in Debrebirehan Referral Hospital, Debrebirehan Town, north Shoa zone, Amhara region, Ethiopia. jourlib org J. 2014;1(1):1-14.

16. Gizaw Z, Woldu W, Bitew BD. Child feeding practices and diarrheal disease among children less than two years of age of the nomadic people in Hadaleala district, afar region, northeast Ethiopia. Int Breastfeed J. 2017;12(1):24.

17. Federal Ministry of Health, Family Health Department Ethiopia. National strategy for infant and young child feeding. Addis Ababa: Federal Ministry of Health, Family Health Department Ethiopia; 2004.

18. Government of the Federal Democratic and Republic of Ethiopia: National Nutrition Program June 2013-June 2015. 
19. Ethiopia National Expanded Programme on Immunization. Comprehensive multi-comprehensive multi-year plan 2016 year plan 2016 year plan 2016-2020. Addis Ababa: Federal ministry of health; 2015.

20. Abebe A, Teka T, Kassa T, Seheri M, Beyene B, Teshome B, Kebede F, Habtamu A, Maake L, Kassahun A, Getahun M. Hospital-based surveillance for rotavirus gastroenteritis in children younger than 5 years of age in Ethiopia: 2007-2012. Pediatr Infect Dis J. 2014;33:S28-33.

21. World Health Organization. CHERG-WHO methods and data sources for child causes of death 2000-2012. 2014.

22. Central Statistical Authority [Ethiopia] and ORC Macro. Ethiopia Demographic and Health Survey 2005. Addis Ababa: Ethiopia and Calverton; 2005

23. Central Statistical Authority [Ethiopia] and ORC Macro. Ethiopia Demographic and Health Survey 2011. Addis Ababa: Ethiopia and Calverton; 2011.

24. Bahirdar city administration zonal health department, 2015.

25. Anteneh ZA, Andargie K, Tarekegn M. Prevalence and determinants of acute diarrhea among children younger than five years old in Jabithennan district, northwest Ethiopia, 2014. BMC Public Health. 2017;17(1):99.

26. WHO/UNICE. Core questions on drinking-water and sanitation for household surveys; 2008. p. 6-19.

27. Azage M, Kumie A, Worku A, Bagtzoglou AC. Childhood diarrhea in high and low hotspot districts of Amhara region, northwest Ethiopia: a multilevel modeling. J Health Popul Nutr. 2016;35(1):13.

28. Berhe F, Berhane Y. Under five diarrhea among model household and non model households in Hawassa, south Ethiopia: a comparative cross-sectional community based survey. BMC Public Health. 2014;14(1):187.

29. Sonko A, Worku A. Prevalence and predictors of exclusive breastfeeding for the first six months of life among women in Halaba special woreda, southern nations, nationalities and peoples' region/SNNPR/, Ethiopia: a community based cross-sectional study. Archives Publ Health. 2015;73(1):53.

30. O'Ryan M, Giaquinto C, Benninghoff B. Human rotavirus vaccine (Rotarix): focus on effectiveness and impact 6 years after first introduction in Africa. Expert Rev Vaccines. 2015;14(8):1099-112.

31. Gupta A, Sarker G, Rout AJ, Mondal T, Pal R. Risk correlates of diarrhea in children under 5 years of age in slums of Bankura, west Bengal. J Global Infect Dis. 2015;7(1):23.

32. Ayele A, Awoke W, Tarekegn M. Crossectional survey; assessment of diarrheal disease prevalence and the associated factors among children under five in Enemay district, northwest Ethiopia. Global J Med Res. 2014;13: 0975-5888.

33. Moya J, Bearer CF, Etzel RA. Children's behavior and physiology and how it affects exposure to environmental contaminants. Pediatrics. 2004;113(Supplement 3):996-1006.

Ready to submit your research? Choose BMC and benefit from:

- fast, convenient online submission

- thorough peer review by experienced researchers in your field

- rapid publication on acceptance

- support for research data, including large and complex data types

- gold Open Access which fosters wider collaboration and increased citations

- maximum visibility for your research: over $100 \mathrm{M}$ website views per year

At $\mathrm{BMC}$, research is always in progress.

Learn more biomedcentral.com/submissions 